\title{
DP-DQPSK Optical Access System Integrated with Fiber and Free-Space Downlink for High Spectral Efficiency Application
}

\author{
Yufeng Shao*, Fuping Chen, Luo Chen, Shilu Shen, Anrong Wang, Yingxiang Luo, Zefu Tan \\ College of Electronic and Information Engineering, Chongqing Three Gorges University, Chongqing, China \\ Email: "syufeng@163.com
}

Received 31 May 2016; accepted 21 August 2016; published 25 August 2016

\begin{abstract}
In this letter, we present the generation, the balanced detection, and the transmission performance evaluation of dual polarization differential quadrature phase shift keying (DP-DQPSK) signals in optical access system integrated with fiber and free-space downlink. Polarization-multiplexed (POLMUX) technique is introduced in the system for high spectral efficiency access utilization. $10 \mathrm{~Gb} / \mathrm{s}$ DP-DQPSK downlink signals are successfully transmitted over $50 \mathrm{~km} \mathrm{SMF-28}$ and a $800 \mathrm{~m}$ wireless optical channel under the bad weather condition, such as fog and haze. The results show that the potentiality of DP-DQPSK optical access system is integrated with fiber and freespace downlink for providing flexible user access with high bandwidth efficiency.
\end{abstract}

\section{Keywords}

Free-Space Optical Communication, Optical Access System, Phase Modulation, Spectral Efficiency

\section{Introduction}

Recently, fiber to the building (FTTB), fiber to the office (FTTO), fiber to the home (FTTH), and fiber to the desk (FTTD) offer "the last mile" solution based on optical access network for different broadband communication services closer to various customers [1]. However, future rapid growth of internet data process and services for mass market customers and business applications puts high capacity demand on optical access systems. As we know, radio over fiber (RoF) system has been researched and it can resolve the scarcity of available bandwidth [2] [3]. Moreover, RoF can transmit radio frequency (RF) signals over one fiber through performing linear electro-optical conversion and returning the signals to electrical domain at the receiver with the radio format [4]. Though RoF has many advantages, it is not feasible because the up conversion and down conversion between the central office (CO) and the base stations (BSs) with micro- or pico-cellular horn antennas are necessary [5] [6], which are very complex and its cost budget is high, since some high-frequency microwave components are essential. The characteristic is not compatible with the current telecommunication transmission network, because the baseband data signals are often transmitted and received in the existing telecommunication transmis-

${ }^{*}$ Corresponding author.

How to cite this paper: Shao, Y.F., Chen, F.P., Chen, L., Shen, S.L., Wang, A.R., Luo, Y.X. and Tan, Z.F. (2016) DP-DQPSK Optical Access System Integrated with Fiber and Free-Space Downlink for High Spectral Efficiency Application. Optics and Photonics Journal, 6, 108-113. http://dx.doi.org/10.4236/opj.2016.68B018 
sion system [7]-[9]. Hence, sufficiently high data rate baseband transmission with high bandwidth efficiency and full seamless integration of wired and wireless links is essential. Free space optical communication (FSO) can provide broadband wireless optical connectivity, and FSO link can be especially designed for particularly space access applications in low-population and rural areas, behind mountains, or across rivers, highways and railways between the optical network unit (ONU) and the optical line terminal (OLT) to serve various users, as shown in Figure 1. FSO systems can also minimize size, weight and power (SWaP) while it is integrated in optical access systems. Optical access systems may adopt phase modulation signal as an efficient transmitted signal because it can operate at almost $3 \mathrm{~dB}$ lower received optical signal noise ratio (OSNR) [10]. Recently, we demonstrated two types of modulation format which combines the well-known techniques of differential phase shift keying (DPSK), differential quadrature phase shift keying (DQPSK), and multiple-input multiple-output (MIMO) wireless transmission for seamless integration of RZ-DPSK-DWDM optical Links with MIMO-OFDM access system [8] [9]. But, in the above schemes, the optical-electro conversion and the electro-optical conversion are necessary for broadband signals transmission and reception, and the corresponded operation will increase the cost budget. For simplifying the optical-electro configuration close to users, FSO is introduced for achieving "the last mile” access in this scheme. Moreover, compared with the traditional formats such as NRZ, DPSK and DQPSK, the DP-DQPSK signal has higher spectrum efficiency and will achieve high data rate information transmission with lower bandwidth for free space wireless access applications. Hence, DP-DQPSK optical access system integrated with fiber and free-space downlink can offer flexible broadband access.

\section{System Setup}

The setup for the seamless integration of DP-DQPSK optical fiber link with FSO communication system is shown in Figure 2. At the transmitter, a continuous-wave (CW) light beam from a distributed feedback (DFB) laser diode (line-width $\sim 1 \mathrm{MHz}$, work frequency at 193.1THz) is fed into a polarization splitter. The CW light is divided into equal two parallel optical carriers. For each optical carrier, two cascaded phase modulators (PM1 and PM2, or PM3 and PM4) with $\pi$ and $\pi / 2$ phase shift are used to generate QPSK optical signals. $1.25 \mathrm{Gbaud} / \mathrm{s}$ original data1anddata 2 are serial to parallel transformed and DQPSK precoded and input four phase modulators respectively to generate two independent DPQSK signals. And then, two DQPSK signals are combined through a polarization splitter combiner to generate a DP-DQPSK signal. Generated $10 \mathrm{~Gb} / \mathrm{s}$ DP-DQPSK signals are transmitted over one 50-km single mode fiber (SMF)(the fiber input power is $2 \mathrm{dBm}$ ) and amplified by one erbium-doped optical fiber amplifier $\left(\mathrm{EDFA}_{1}\right)$ for compensating the transmission attenuation. We apply commonly used fiber parameters in this work: fiber chromatic dispersion (CD) of $16.1 \mathrm{ps} / \mathrm{nm} / \mathrm{km}, 0.2 \mathrm{~dB} / \mathrm{km}$ loss, and a nonlinear coefficient of $2.6 \times 10^{-20} \mathrm{~m}^{2} / \mathrm{W}$, as shown in Table 1 .

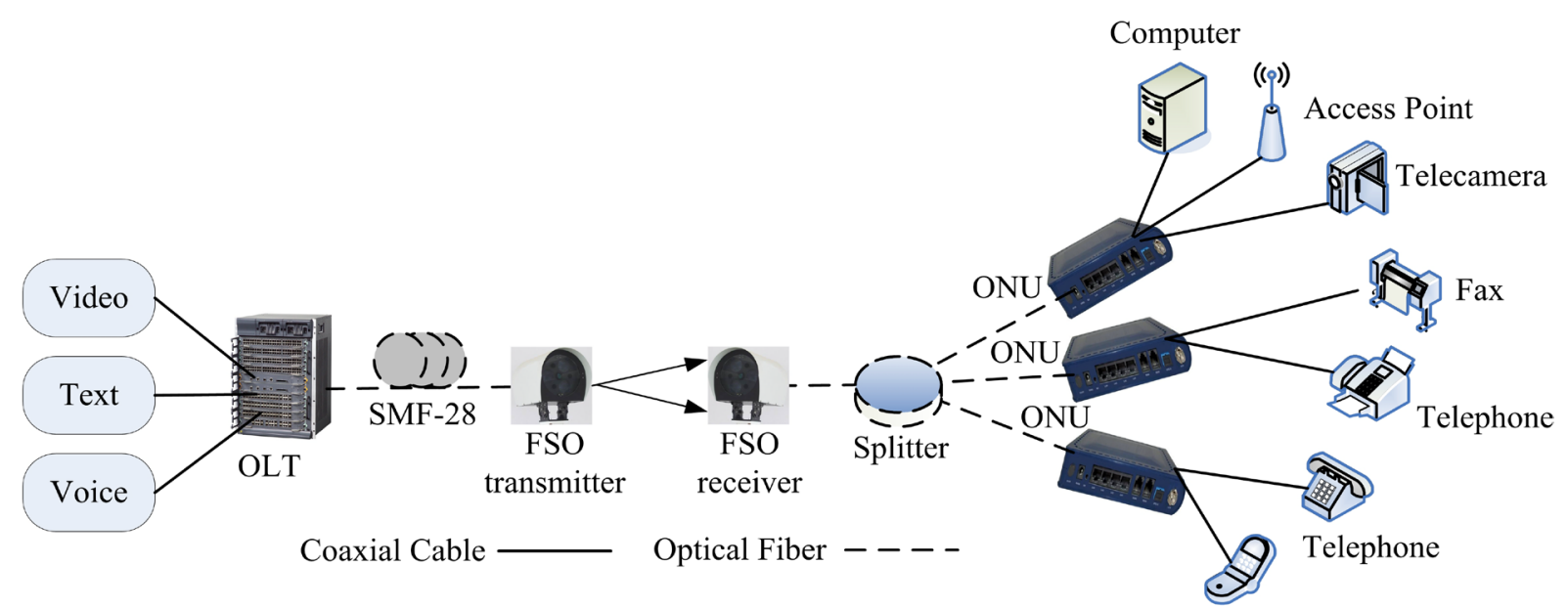

Cell Phone

Figure 1. Optical access system with fiber and FSO downlink (OLT: optical line terminal; SMF: single mode fiber; ONU: optical network unit). 


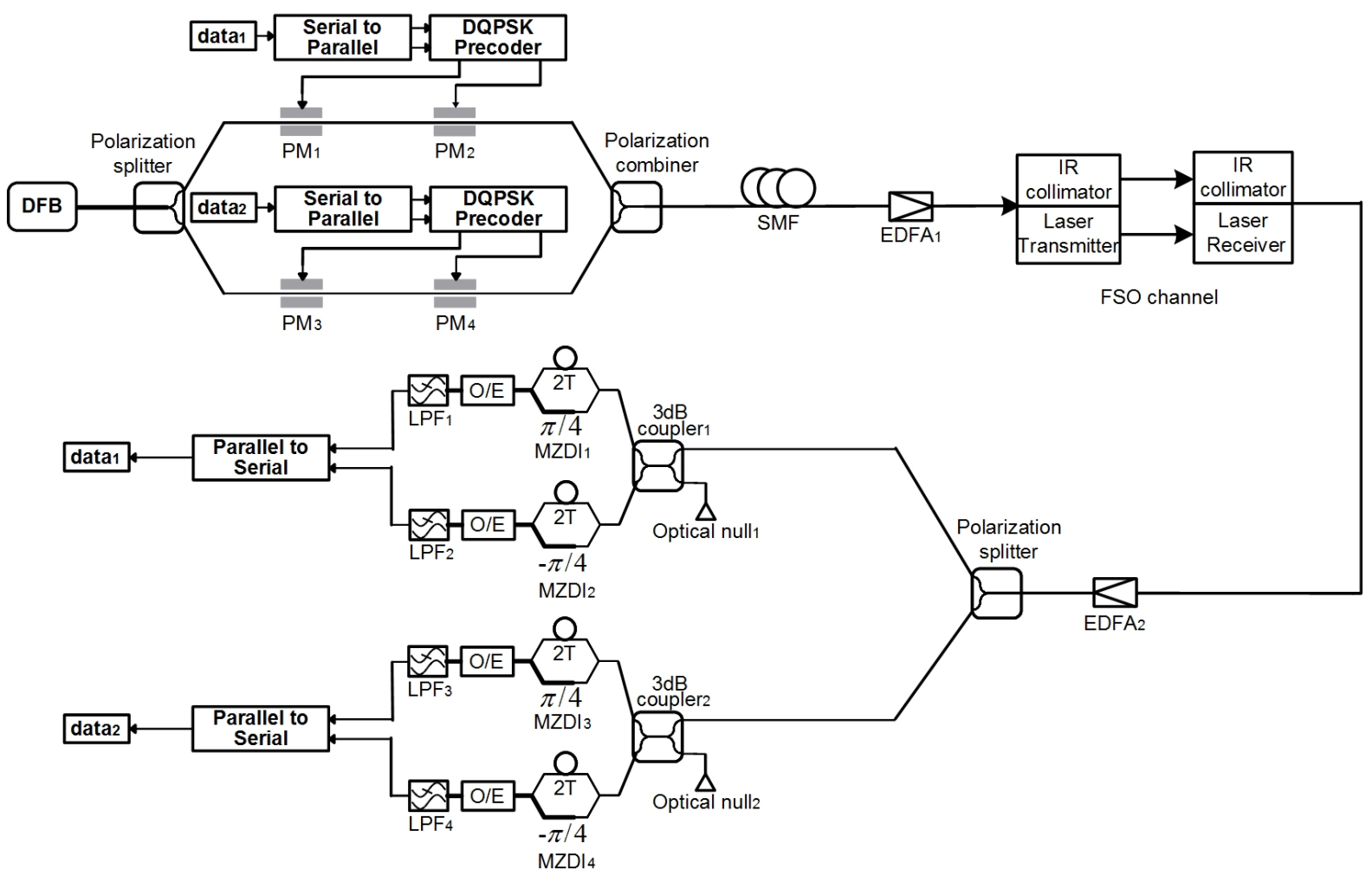

Figure 2. System configuration (DFB: distributed feedback laser, PM: phase modulator, SMF: single mode fiber, EDFA: erbium-doped optical fiber amplifier, FSO: free space optical communication, MZDI: Mach-Zehnder delay interferometer, O/E: optical to electrical converter, LPF: low pass filter).

Table 1. Optical fiber parameters.

\begin{tabular}{cc}
\hline Parameters & SMF-28 \\
Length $(\mathrm{km})$ & 25 \\
Attenuation $(\mathrm{dB} / \mathrm{km})$ & 0.2 \\
Dispersion $(\mathrm{ps} / \mathrm{nm} / \mathrm{km})$ & 16 \\
Dispersion slop $\left(\left(\mathrm{ps} / \mathrm{nm}^{2} / \mathrm{km}\right)\right.$ & 0.08 \\
Nonlinear coefficient $\left(\mathrm{W}^{-1} \cdot \mathrm{km}^{-1}\right)$ & 2.6 \\
Core area $\left(\mu \mathrm{m}^{2}\right)$ & 84.9 \\
\hline
\end{tabular}

After optical amplification, $10 \mathrm{~Gb} / \mathrm{s}$ DP-DQPSK signals are input FSO transmission system. This system is a subsystem of IR collimator, transmitter telescope, free space link and receiver telescope. The aperture diameter of the transmitter telescope is $5 \mathrm{~cm}$, and the value of the receiver aperture diameter is $5 \mathrm{~cm}$. At the transmitter, the fiber-telescope coupling and transmitter efficiency losses are $1 \mathrm{~dB}$. Similarly, the receiver loss is also $1 \mathrm{~dB}$. The free space link distance between the transmitter and the receiver telescopes is $800 \mathrm{~m}$, and the beam divergence is $0.25 \mathrm{mrad}$. The values of the attenuation coefficient for various weather conditions are different. Considering the bad weather condition, such as fog and haze, the free space transmission attenuation caused by atmospheric effects is almost $25.5 \mathrm{~dB} / \mathrm{km}$, as shown in Table 2 .

After $10 \mathrm{~Gb} / \mathrm{s}$ DP-DQPSK signals pass through the FSO link and coupled by one connected SMF, the second $\mathrm{EDFA}_{2}$ is used to connect the SMF for compensating the free space transmission attenuation. And then, DPDQPSK signals is split two optical paths by one polarization splitter for demodulation. In each demodulation path, the DQPSK demodulator includes one $3 \mathrm{~dB}$ coupler, two Mach-Zehnder delay interferometers (MZDIs), 
Table 2. FSO link parameters.

\begin{tabular}{cc} 
Parameters & FSO link \\
Length $(\mathrm{m})$ & 800 \\
Attenuation $(\mathrm{dB} / \mathrm{km})$ & 25.5 \\
The transmitter aperture diameter $(\mathrm{cm})$ & 5 \\
The receiver aperture diameter $(\mathrm{cm})$ & 5.25 \\
The beam divergence (mrad) & 1 \\
The insert loss in the transceiver $(\mathrm{dB})$ & 1 \\
\hline
\end{tabular}

two photodiodes for optical to electrical conversion and two third-order Bessel low pass filters (LPF). All of the cutoff frequency values of the used low pass filters are $1.25 \mathrm{GHz}$. For each optical path, the obtain data is parallel to serial transformed for restoring original transmitted data ( data $_{1}$ or data $)_{2}$.

\section{Results and Analysis}

In our scheme, the time-domain phase change diagrams of DP-DQPSK signals before and after transmission over fiber and FSO link are extracted to evaluate the system performance, as show in Figure 3(a) and Figure 3(b). It is clear to see, the transmitted and received DP-QPSK optical signals phase diagrams have same phase change curves, and the received optical signals exhibit slightly phase change due to chirp effect. Two optical spectra diagrams of DP-DQPSK signal before transmission and after transmission are shown in Figure 3(c) and Figure 3(d) respectively. In the system, though two EDFAs are used to compensate the transmission attenuation, there are insert loss in two cascaded phase modulators, the transmitter telescope and the receiver telescope. Hence, the received optical power is lower than fiber nput power. Two received eye diagrams of DP-DQPSK signal after $50.8 \mathrm{~km}$ transmission over $50 \mathrm{~km}$ SMF and 800m FSO downstream are shown in Figure 4(a) and Figure 4(b) respectively for recovery data1 or $\mathrm{data}_{2}$, and the received eyes are clear open. $\mathrm{Q}$ factors $\mathrm{v} / \mathrm{s}$ bit period for data 1 or data ${ }_{2}$ of DP-DQPSK signals are shown in Figure 5(a) and Figure 5(b). For data ${ }_{1}$, Q factor value is good while $3 \mathrm{R}$ signal process is performed and the optimal decision point of the demodulated signal is 0.56 bit time. Note that, the obtained diagrams of Figure 4 and Figure 5 are in the case of BER $=10^{-6}$. It is found that, the transmission impairments are introduced while a DP-DQPSK signal passes through the integrated SMF and FSO downlink since the degradation of optical signal noise ratio (OSNR), and the decision point choice for getting the best $\mathrm{Q}$ value is necessary, since the recovered data by the optimal decision will be allocated to different users for various access applications. The BER v/s received power curves for this scheme are shown in Figure 6. The insert picture is the received signals constellation diagram after SMF and FSO transmission as the received power is $-13 \mathrm{dBm}$. At the end of $50 \mathrm{~km}$ SMF-28 and $800 \mathrm{~m}$ FSO channel, the receiver sensitivity is $-15.3 \mathrm{dBm}$ (at a BER of $10^{-6}$ ). Compared with the back to back case, the value of the received power penalty at $\mathrm{BER}=10^{-6}$ will be reduced, which is about $3 \mathrm{~dB}$.

\section{Conclusion}

In this letter, we proposed and demonstrated a scheme to seamlessly integrate optical fiber link with FSO system for "the last mile" solution based on optical access network for different broadband communication services closer to various customers. Results prove the BER performance of almost 10-6 can be achieved with the downlink of optical fiber, the transmitter telescope, the free space link and receiver telescope. Since this scheme is not complex and the cost budget is low and it is well compatible with the current telecommunication transmission system, it is a competitive scheme in future optical access networks.

\section{Acknowledgements}

This work is partially supported by the National Natural Science Foundation of China (No. 61107064), the Chongqing University Innovation Team Founding (No. KJTD201320), the Chongqing Science and Technology 


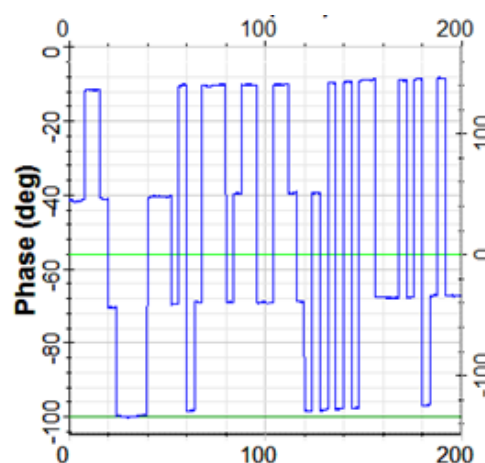

(a) Time (bits)



(c) Frequency $(\mathrm{Hz})$

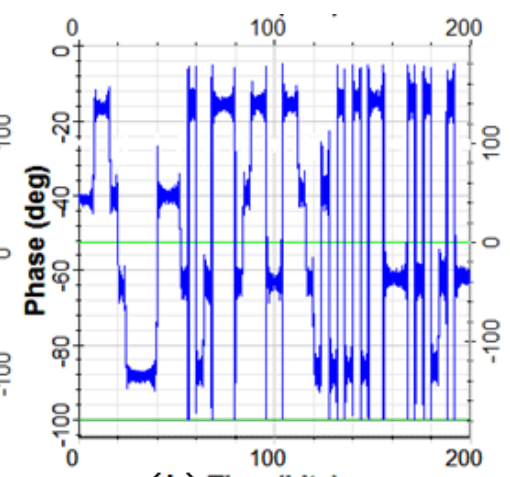

(b) Time (bits)

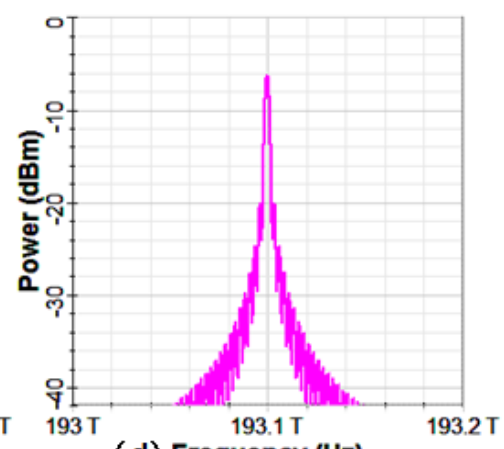

(d) Frequency $(\mathrm{Hz})$

Figure 3. Time-domain phase change diagrams of DP-DQPSK signals before (a) and after (b) transmission over fiber and FSO link, optical spectra diagrams of DP-DQPSK signals before (c) transmission and after transmission (d).

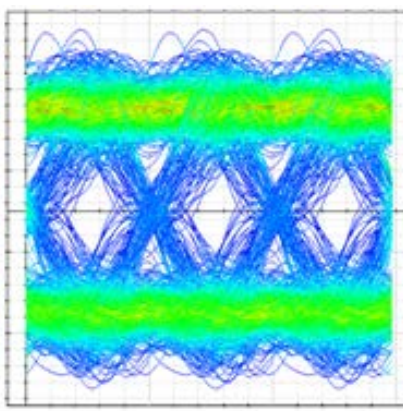

(a) Eye diagram (data $)_{1}$

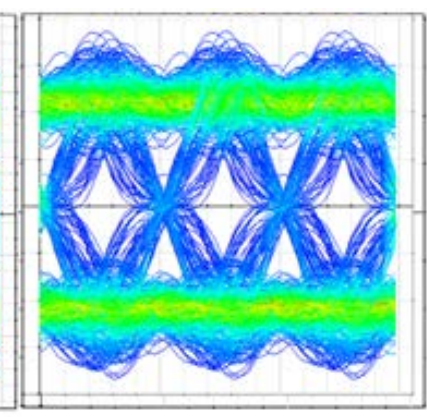

(b) Eye diagram $\left(\right.$ data $\left._{2}\right)$

Figure 4. Two eye diagrams of DP-DQPSK signal after $50.8 \mathrm{~km}$ transmission over $50 \mathrm{~km}$ SMF and 800m FSO downstream.



(a) $Q$ factors $\left(\right.$ data $\left._{1}\right)$

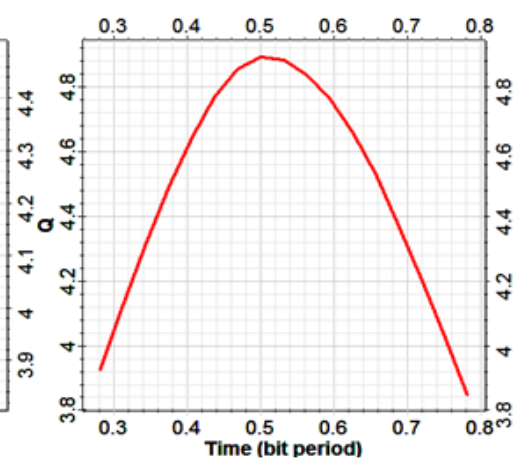

(b) $Q$ factors $\left(\right.$ data $\left._{2}\right)$

Figure 5. Q factors v/s bit period for data or data $_{2}$ of DP-DQPSK signals. 


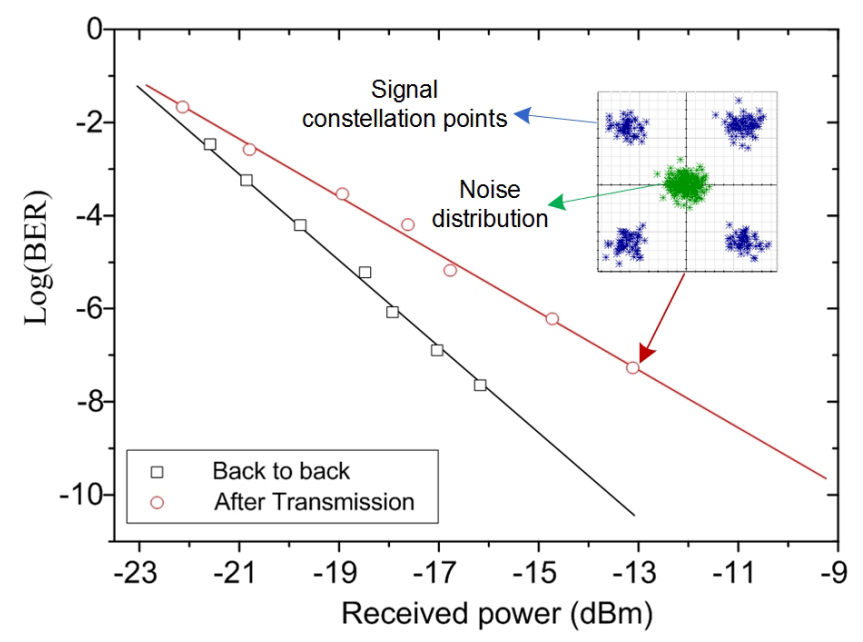

Figure 6. Received power versus BER after detecting DP-DQPSK signals.

Commission Foundation (No. cstc2014jcyjA 40046), the Science and Technology Special Funds in Wanzhou District, and the Chongqing Graduate Scientific Research Innovation Project (No. CYS15225).

\section{References}

[1] Tomkos, L. Kazovsky, K. Kitaiama (2012) Next-Generation Optical Access Networks: Dynamic Bandwidth Allocation, Resource Use Optimization, and QoS Improvement. Guest Editorial IEEE Networks, 26, 2, 4-6.

[2] Shao, Y., Huang, B., Chi, N., et al. (2010) A Novel Subcarrier OFDM-MSK WDM Passive Optical Network. IEEE Optical Fiber Communication Conference and Exposition (OFC).

[3] Shao, Y. and Chi, N. (2011) Generation of OFDM-MSK Signal and Its Application for Radio over Fiber System in Future Access Network. IEEE CMC, 206-209.

[4] Mostafa, S. Harnilovic, (2012) In-Field Demonstration of OFDM-FSO. IEEE Photonics Technology Letters, 24, 709711. http://dx.doi.org/10.1109/LPT.2012.2187279

[5] Shao, Y., Wang, Y. and Chi, N. (2013) 60-GHz RoFsystem with Low PAPR 16QAM-OFDM Downlink Using PTS Segmentation. IEEE Photonics Technology Letters, 25, 855-858. http://dx.doi.org/10.1109/LPT.2013.2252425

[6] Shao, Y., Chi, N., Fan, J., et al. (2012) Generation of 16-QAM-OFDM Signals Using Selected Mapping Method and Its Application in Optical Millimeter-Wave Access System. IEEE Photonics Technology Letters, 24, 1301-1303. http://dx.doi.org/10.1109/LPT.2012.2202387

[7] Abdollahi, S. R., Al-Raweshidy, H. S., Nilavalan, R., et al. (2011) An Integrated Transportation System for Baseband Data, Digital and Analogue Radio Signals over Fiber Network. Wireless Communications and Mobile Computing Conference (IWCMC), 2003-2008.

[8] Shao, Y., Wang, S. and Tan, Z. (2014) Seamless Integration of RZ-DQPSK-DWDM Optical Links with MISOOFDM-QPSK System for 4th Generation Wide-Area Coverage Mobile Communication. Microwave and Optical Technology Letters, 56, 797-801. http://dx.doi.org/10.1002/mop.28201

[9] Shao, Y. and Chi, N. (2012) A Novel Scheme for Seamless Integration of RZ-DPSK-DWDM Optical Links with MIMO-OFDM System. Microwave and Optical Technology Letters, 54, 7, 1676-1679. http://dx.doi.org/10.1002/mop.26891

[10] Shao, Y., Chi, N., Hou, C., et al. (2010) A Novel Return-to-Zero FSK Format for 40-Gb/s Transmission System Applications. IEEE Journal of Lightwave Technology, 28, 1770-1782. http://dx.doi.org/10.1109/JLT.2010.2048413 


\section{Submit or recommend next manuscript to SCIRP and we will provide best service for you:}

Accepting pre-submission inquiries through Email, Facebook, LinkedIn, Twitter, etc.

A wide selection of journals (inclusive of 9 subjects, more than 200 journals)

Providing 24-hour high-quality service

User-friendly online submission system

Fair and swift peer-review system

Efficient typesetting and proofreading procedure

Display of the result of downloads and visits, as well as the number of cited articles

Maximum dissemination of your research work

Submit your manuscript at: http://papersubmission.scirp.org/ 